\title{
Long-Term Variations in Infrasound Signals Observed at Syowa Station, Antarctica: 2008-2014
}

\section{Yoshiaki Ishihara1 ${ }^{*}$, Masa-Yuki Yamamoto², Takahiko Murayama3 ${ }^{3}$, Takeshi Matsushima4, Masaki Kanao 5}

${ }^{1}$ Institute of Space and Astronautical Science, Japan Aerospace Exploration Agency, Sagamihara-shi, Japan

${ }^{2}$ Kochi University of Technology, Kami-shi, Japan

${ }^{3}$ Japan Weather Association, Tokyo, Japan

${ }^{4}$ Faculty of Sciences, Kyushu University, Nagasaki, Japan

${ }^{5}$ National Institute of Polar Research, Research Organization of Information and Systems, Tokyo, Japan

Email: ${ }^{*}$ ishihara.yoshiaki@jaxa.jp

How to cite this paper: Ishihara, Y., Yamamoto, M.-Y., Murayama, T., Matsushima, T. and Kanao, M. (2017) Long-Term Variations in Infrasound Signals Observed at Syowa Station, Antarctica: 2008-2014. Inframatics, 3, 1-10.

https://doi.org/10.4236/inframatics.2017.31001

Received: February 1, 2017

Accepted: March 2, 2017

Published: March 5, 2017

Copyright $\odot 2017$ by authors and Scientific Research Publishing Inc. This work is licensed under the Creative Commons Attribution International License (CC BY 4.0).

http://creativecommons.org/licenses/by/4.0/

(c) (i) Open Access

\begin{abstract}
Long-term Infrasound data at Syowa Station (SYO; 39E, 69S), in the LützowHolm Bay (LHB), East Antarctica was analyzed during the period from 2008 to 2014. Seasonal variations in microbaroms and high-frequency harmonic tremors were especially investigated. Infrasound data were strongly involved in local dynamics of surface environments. The microbaroms have relatively low amplitudes in austral winters by extending area of sea-ice around LHB, with decreasing oceanic swell loading effects. The other reasons of seasonal variations in microbaroms amplitudes were caused by the affections of a number of storms during whole year and snow accumulation over the porous hoses on the infrasound station at SYO. In contrast, non-linear high-frequency harmonic tremors were considered to be caused by the katabatic winds from Antarctic continent flowing in northeast dominant orientation. The high-frequency tremors had characteristics of daily variations in particular in austral summer. It is required to continue more than a few years of observation in order to identify relationships with climate change and global warming effects in the Antarctic. Continuous measurement of infrasound in the coastal margin of Antarctica is a proxy for monitoring multi-sphere interaction between the continent and surrounding Southern Ocean.
\end{abstract}

\section{Keywords}

Infrasound, Long-Term Monitoring, Antarctica, Surface Environment, Microbaroms, High-Frequency Tremors 


\section{Introduction}

"Infrasound" is attributed as a sub-audible pressure wave with frequency from the cut-off of a sound $\left(3.21 \mathrm{mHz}\right.$, for a $15^{\circ} \mathrm{C}$ isothermal atmosphere) to the lowest of the human audible band $(20 \mathrm{~Hz})$, and the wave can be excited by large energy which propagates for several thousand kilometers along the Earth's surface [1]. This frequency range is a new horizon for the remote sensing of physical environment of the atmosphere and there are many examples of infrasound excitation by several generating sources; volcanic eruptions, ocean waves, earthquakes and tsunamis, aircraft passage, thunder and sprites, meteorite falls and fireballs, reentry of artificial vehicles, aurora activities, etc. [2]-[7]. Simultaneous observations of infrasound and seismic waves were, moreover, conducted in order to detect shock waves by large meteorites over Japanese island [8], as well as the artificial hypersonic reentry of the "Hayabusa" capsule [9] [10].

In polar region, time-space variations in atmospheric pressure are generated by physical interaction among multi-spheres (atmosphere, oceans, cryosphere, and solid earth [11]. The interaction is strongly involved in surface environmental change and their exciting sources are measured by infrasound. In April 2008, infrasound observations started at Syowa Station (SYO; 69.0S, 39.6E), in the Lützow-Holm Bay (LHB), East Antarctica. The single infrasound sensor at SYO has been continuously recording the data for many seasons since the beginning in 2008, and has been clearly recorded contamination signals from oceanic swells (microbaroms) [12]. Variability in power spectrograms were demonstrated for the first three years from the start of infrasound observations (2008-2010) [13].

During austral summer in 2013, several field stations were established along the eastern coast of LHB. In particular, two infrasound arrays were deployed; one array was on the outcrop inside SYO including the operating station from 2008 as one of the array station; the other array was set on the continental ice sheet at eastern coast of LHB [14]. By using these array configurations, identification of infrasound sources was tried to detect seven identical events for the period in January-June, 2015 [15]. Many of the sources were assumed to be cryoseismic origins; the ice-quakes associated with calving glaciers, discharge of sea-ice, and collision between icebergs around LHB.

In this paper, following the previous study, more long-term variations of infrasound signals are investigated so as to compare the environmental changes nearby the area. Actually, seven years of data from the beginning of observation at SYO on April 2008 to the end of 2014 are demonstrated. In particular, seasonal variations in their amplitudes and frequency contents, as well as characteristic high-frequency tremor signals associated with surface environments (cryosphere, oceans and shallow atmosphere) nearby the station are investigated. 


\section{Infrasound Data Recording System}

An infrasound sensor was at first installed on an exposed metamorphic rock site near the seismographic hut of SYO in April 2008, where is inside the East Ongul Island, in LHB [13]. The Chaparral Physics Model-2 infrasound sensor (condenser microphone type) was deployed inside an adiabatic wooden box, attached by eight single-connected-type air-pipes (porous hoses). The hose array structure alignment aimed to reduce the wind noises by adopting the mechanical lowpass filtering.

Five years later, a tripatite array was established at SYO with diameter of 100 m spacing in January 2013 [14]. The Chaparral Physics Model 25 (manufactured by the University of Alaska, USA, with a detectable frequency range of $0.1-200$ $\mathrm{Hz}$ ) has been used from January 2013 for all the array stations. The Chaparral Physics Model-2 infrasound sensor, which had been operating since 2008, was replaced to the new one of the Chaparral Physics Model 25 at the time. At the SYO array sites, multiply-connected porous hose structures have been aligned to reduce wind noises by adopting mechanical low-pass filtering since January 2013. Most portions of the porous hoses were buried beneath the stone mounds which were collected from nearby the sites in order to reduce the vibration effect from wind noises.

The recorded infrasound signals were transferred from the three sensors to a data-logger (Datamark LS7000-XT, by Hakusan Co.) in the seismographic hut via analog cables. The analog data were digitized with sufficiently high sampling rate of $100 \mathrm{~Hz}$ with a wide dynamic range of $120 \mathrm{~dB}$ (24 bits), and stored in a compact flash (CF) card (4 GB). The stored data in the logger are automatically transmitted to the Linux server (Open Block S266) inside the same seismological hut, connecting by a LAN of the station. After accumulating inside the Linux server, the infrasound data have been transmitted to Japan by Intersat communication system between SYO and the National Institute of Polar Research (NIPR) in Tokyo. Detail descriptions about the aquisition system were written in [13] and [14].

\section{Long-Term Characteristics of Infrasound Data}

Figure 1 represents the dynamic power spectral densities (PSD) of the infrasound signals for seven years (2008-2014) from the beginning of pilot observations at SYO (the data for one of the array sites; C1; see the details in [14]). The PSD were calculated from the spectral densities of 5 minutes of time-windows by overlapping their band window (2.5 minutes), following re-sampled by two-hour intervals for the all continuous waveform data. The white colored time zones correspond to those when the lacking of data by any reasons, otherwise any errors occurred during the PSD calculating processing. Predominant frequencies corresponding to "microbaroms" $(0.1-0.3 \mathrm{~Hz})$ are clearly identified as continuous signals during the whole seasons of recording periods. Moreover, there can slightly be identified time variations in predominant frequency contents and 


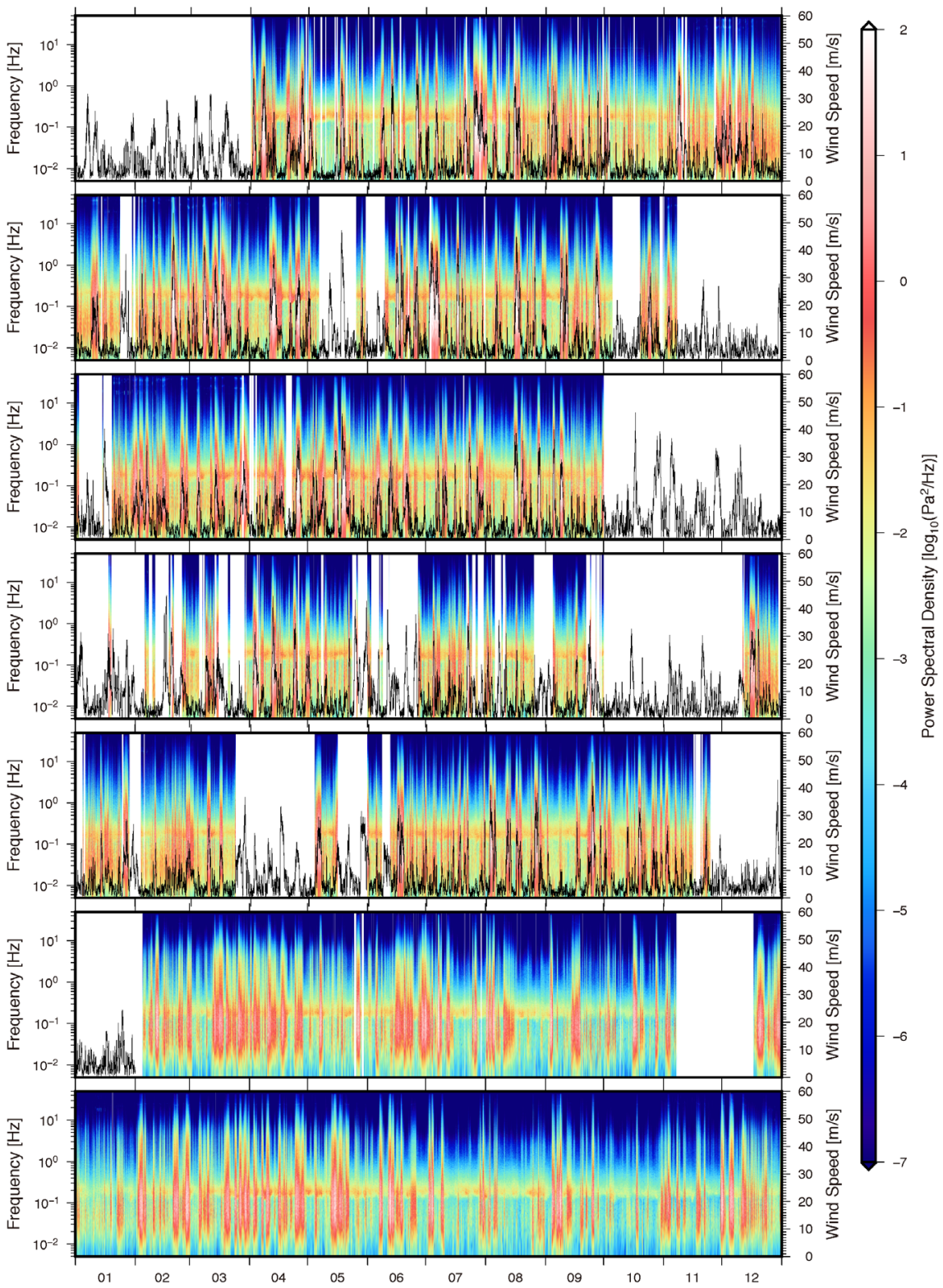

Figure 1. Power spectral densities (PSD) of infrasound signals for seven years (20082014) from the beginning of pilot observations at Syowa Station (SYO; one of the array sites; C1; [14]). The white colored time zones correspond to the lack of data, otherwise any errors occurred during the PSD processing. Predominant frequencies corresponding to the microbaroms are clearly identified during the recording periods. The horizontal axis is the month of the year. The wind speed data at SYO (from Japanese Meteorological Agency; JMA) are overlapped on the PSD.

amplitudes in the microbaroms. The wind speed at SYO (provided by Japanese Meteorological Agency; JMA) are also overlapped on the PSD. By comparing with the wind data, it is clearly found that the periods of high amplitude in PSD correspond to those when a couple of storms visited to SYO.

Time variations in PSD energy of the infrasound signals for frequency bands corresponding to the microbaroms $(0.1-0.3 \mathrm{~Hz})$ during the seven years are illustrated in Figure 2. Except for the arrival periods of several storms attributed by 


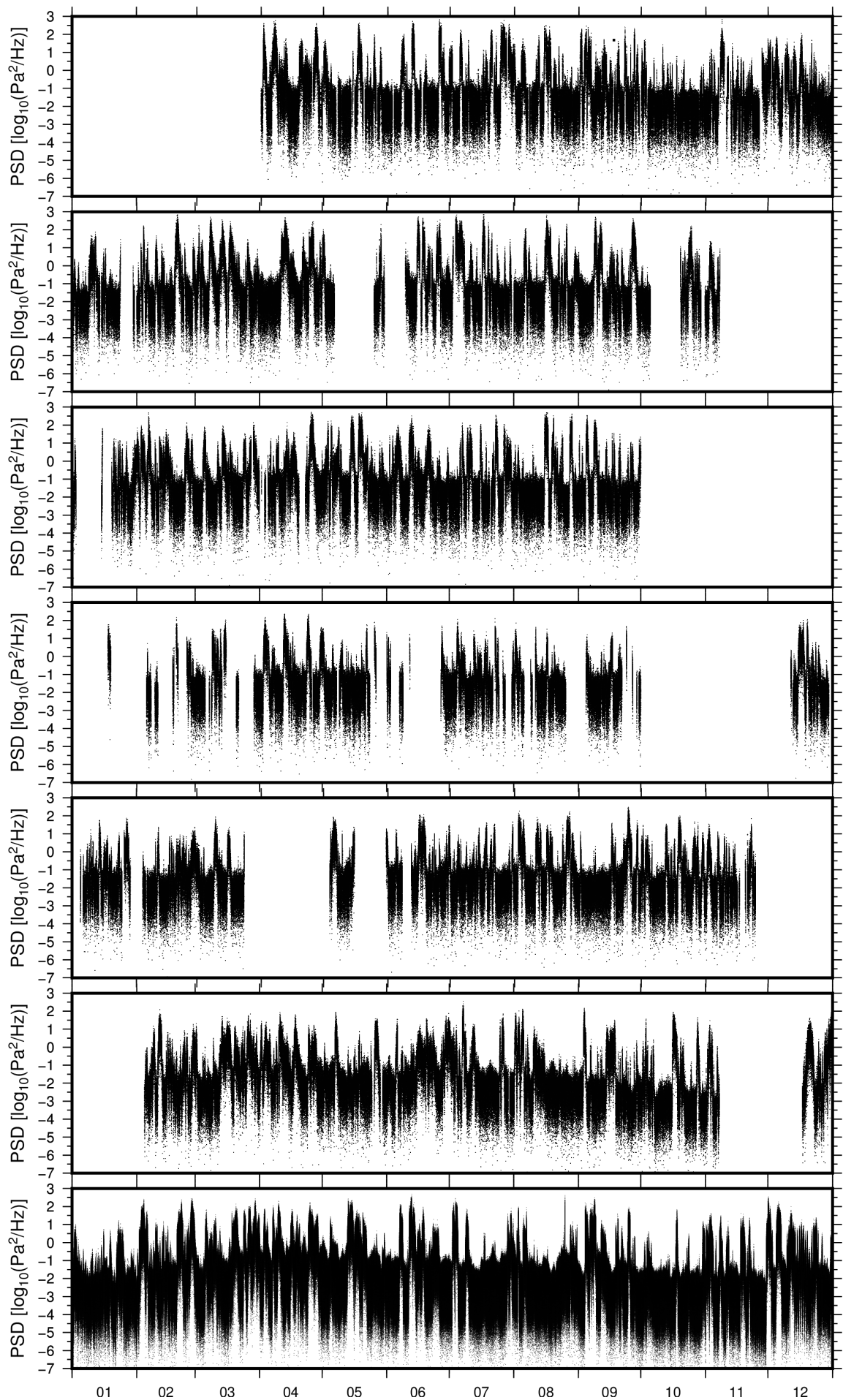

Figure 2. Time variations in power spectral densities (PSD) of infrasound signals for the frequency bands corresponding to microbaroms $(0.1-0.3 \mathrm{~Hz})$ during seven years (20082014) at SYO. Except for the arrival periods of storms with high energy of PSD, seasonal variations for each year are identified.

high amplitudes (+2 - +3 in PSD energies) in all frequency bands, seasonal variations in PSD were recognized for every year. These seasonal variations were characterized by high energy in austral winter, in contrast low energy in austral 
summer. The seasonal variations in PSD amplitudes were assumed to be the effect of the highest visiting season of the storms in particular austral autumn (March, April, and May), when the averaged signal level of the microbaroms could be larger than the other seasons. The second reason was the seasonal variation of sea-ice spreading area and thickness surround LHB. These seasonal evolutions of sea-ice (both fast sea-ice and packed sea-ice) also affected significantly to the "microseismic" energy on seismographs at SYO [15]. The third reason might be the effect of snow accumulation over the porous hoses at the infrasound observation sites. That is, gradual increase of the snow accumulation toward the austral spring season could decrease the noise level of infrasound signals. A combination of these factors could make the seasonal changes in PSD.

\section{Short-Term Characteristics of Infrasound Data}

Characteristics of infrasound observation at SYO were attributed by utilizing the high-sampling $(100 \mathrm{~Hz})$ data acquisition system [13]. The acquisition frequency ranges covered all frequency bands from the maximum to the lowest audible bands of infrasound. By adopting the high-sampling system, several characteristic signals of harmonic long-duration waves were identified. Figure 3 represents the PSD of infrasound signals recorded at SYO during one month of February 2014. High frequency ranges more than $10 \mathrm{~Hz}$ are represented in vertical axis.

High amplitudes in the dynamic power spectral densities appeared at the days corresponging to the storms' visits. Several non-linear harmonic overtone signals with daily variations were also identified in a frequency range more than $20 \mathrm{~Hz}$. The harmonic overtones appeared identically at the stormy days, however, recognized as the small amplitude signals at less windy (fine wheather) days too. The high-frequency harmonic tremors appeared to have daily variations, however, they have not nesessarry attain the harmonic overtone features in any time (i.e., the non-linerar charcteristics).

The windy noise cancelization system by using porus hose array at SYO [14] did not seem to induce the generation of stable current wavelets with highfrequency contents of harmonic overtones. Therefore, natural sources generatied nearby the station sites could be considered as the exciting origins of the highfrequency non-linear signals. Several candidates of the signals were considerable, such as the cryoseismic signals caused by the winds, basal sliding of the sea-ice surroundings, etc. [13]. Figure 4 demonstrates the occurrence rate (\%) of the detected predominant signals at SYO from 10 February to 31 March, 2013 (Modified after [14]). Wind direction of the frequency contents corresponds to that of the microbaroms $(0.1-0.3 \mathrm{~Hz})$ clearly came from NNW, where the offshore of LHB in the Southern Indian Ocean. On the contrary, the signals with high frequency bands more than $1 \mathrm{~Hz}$ mainly came from NE, where the "katabatic winds" flew dominantly from the Antarctic continent to the coastal area of SYO. It is considered that the katabatic winds generated the large energy predominantly appearing in the NE direction at near-surface layer of the atmosphere under the stormy conditions. The katabatic winds have a feature of daily varia- 


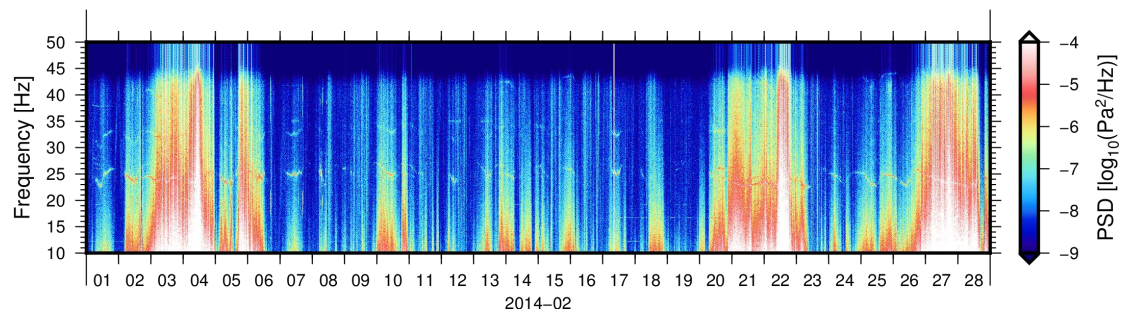

Figure 3. Power spectral densities (PSD) of infrasound signals recorded at SYO during one month of February 2014. High frequency ranges more than $10 \mathrm{~Hz}$ are represented in vertical axis. High amplitudes in spectral densities were appeared at stormy days. Several non-linear harmonic overtone signals with daily variations were also identified more than $20 \mathrm{~Hz}$.

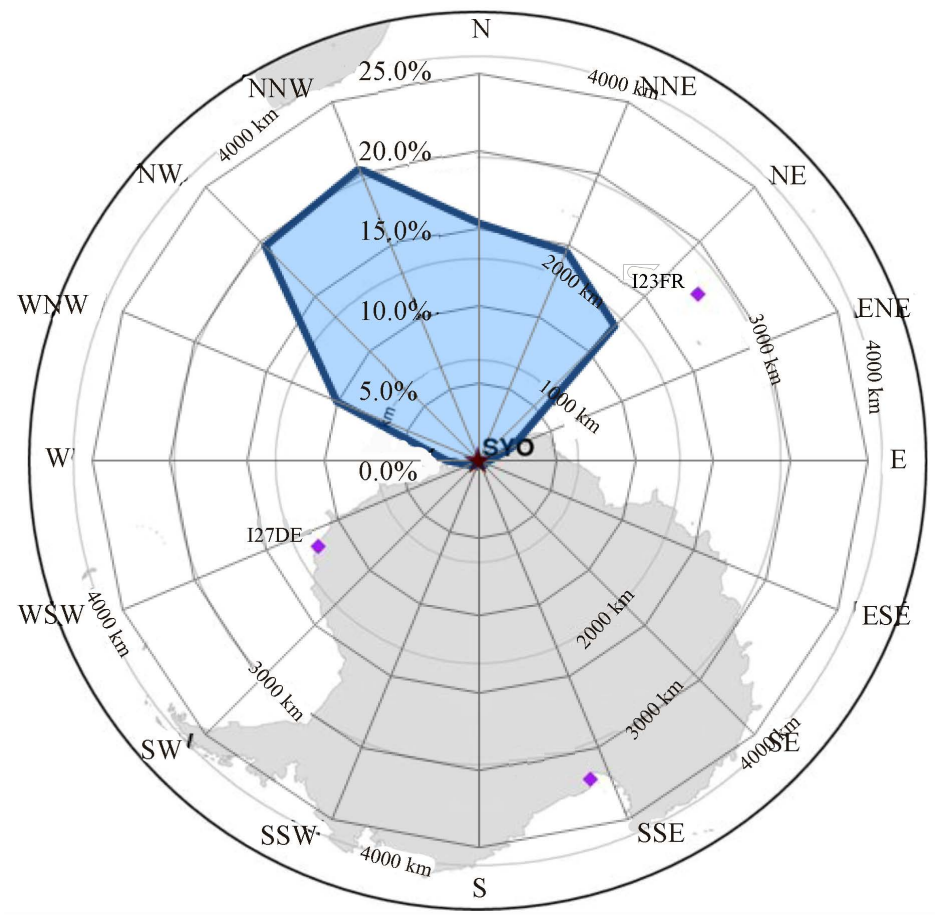

Figure 4. Occurrence rate (\%) of the detected predominant signals at SYO from $10 \mathrm{Feb}$ ruary to 31 March, 2013 (Modified after [14]): a) A polar plot of all frequency bands; b) A polar plots of five different frequency bands. Information of the other CTBTO stations are as follows; I23FR: (Kerguelen, 49.2S, 69.1E), I27DE: (Georg von Neumayer, Antarctica, 70.6S, 8.4W), I55US: (Windless Bight, Antarctica, 77.5S, 161.8E).

tion in austral summer because of the warm air temperature at the coastal area in the Antarctic; which is coincident with the daily variation of the high frequency over-toned signals appeared in infrasound data in February 2014 (Figure $3)$.

\section{Discussion}

Regarding the effect by oceanic swells on infrasound data, the "microbaroms" varied slightly both in amplitude and frequency contents in relatively long-period duration more than few days. These variations correspond to the local atmospheric or weather conditions. Infrasound signals below $3 \mathrm{~Hz}$ frequency content were supposed to contain in some extent the "microbaroms" which can be 
excited by storms over the Southern Ocean during whole season particular in austral winter. However, it is rather identical that the seasonal variation effect by the microbaroms on infrasound data during our studied period in 2008-2014. The seasonal variations in microbaroms amplitude could be the same situation as appearing on the seismographs (microseisms; [16]). The seasonal variations in microseisms are involved strongly with sea-ice extents around LHB, which impede both direct ocean-to-continent coupling and coastal reflection [11].

Along with oceanic-originated microbaroms, characteristic repeating signals occasionally appeared with harmonic overtones at a few tens of $\mathrm{Hz}$ to the lowest human-audible band. The repeating tremor-like signals are visible as shown in Figure 2, which sometimes continue for a few hours to half-a-day or more longer. These long-standing tremor signals consist predominantly of frequency components ranging with several harmonic overtones around 10 to $40 \mathrm{~Hz}$, however, sometimes the frequency extends into the lowermost human audible band and some still into the sub-audible band. In addition, very long standing signals with duration of few days to tens of days during the austral winter seasons are recognized in infrasound PSD at SYO.

Although we could not figure out the generatig source exactly, the amplitudes of harmonic overtone signals were strong under windy conditions. Therefore, it was considered the local phenomena near the ground surface could be induced by the consistent strong wind condition such as the "katabatic" winds from the Antarctic continent. The other probable candidates of generating high-frequency tremor signals could be related to the resonance effect of the observation system such as inside the porous hoses [17], otherwise the wooden box covering the sensor. However, these candidates can be removed because of our recentlyconducted testing measurements by utilizing direct connection between the hoses and the Chaparral sensor inside the wooden box at the site of $\mathrm{C} 1$ (SYO) comparing with the other $\mathrm{C} 2$ and $\mathrm{C} 3$ sites. The high-frequency tremors could also be identified when the direct connection between the hoses and sensor in the wooden box.

By this study, the infrasound observations at SYO have been efficiently operating, and it becomes possible to provide useful information on the long-term variability of surface environment surrounding the LHB. It is also useful to compare these signals with other data, such as the seismic and hydro-acoustics that share sensitivity with the infrasound frequency ranges [18]. The oceanic-atmospheric coupling effects on infrasound signals will consequently be explained by how they are related to the multi-sphere system in polar environment. In this concern, infrasound monitoring in the Antarctic should be a proxy for detecting regional environmental change within global climate variation.

\section{Conclusion}

Infrasound data at Syowa Station, Antarctica were demonstrated in detail from 2008 to 2014, with their seasonal variations in microbaroms amplitudes, together with the appearance of high-frequency harmonic tremors. Characteristics of the 
infrasound data were associated with environmental changes in the vicinity of LHB. Seasonal variations of microbaroms amplitudes were considered to be affected by the combination of sea-ice extent surroundings, number of storms during whole year and snow accumulation effects on the porous hoses of the infrasound station at SYO in austral winter. On the contrary, non-linear highfrequency harmonic tremors were considered to be caused by the katabatic winds from Antarctic continent flowing from northeast dominant orientation. The high-frequency tremors had characteristics of daily variations in particular during austral summer. It is required to continue more than a few years of observations in order to investigate relationships with climate change and global warming effects in the Antarctic.

\section{Acknowledgements}

We would like to express our sincere appreciation to many collaborators for infrasound observations at SYO, as well as related members of the Japanese Antarctic Research Expeditions (JARE). Infrasound observation at SYO was partially supported by the Ministry of Education, Science, Sports and Culture, Grant-in-Aid for Young Scientists (B) 19740265, 2007 (P.I. for Dr. Yoshiaki Ishihara). This work was also supported by JSPS KAKENHI Grand Number 26241010 (P.I. by Dr. Masaki Kanao). We would also like to express sincere appreciation to referees and editorial office of the publisher for their sincere efforts for publishing this paper.

\section{References}

[1] Hedlin, M.A.H. and Garces, M.A., Bass, H., Hayward, C. and Herrin, G., Olson, J.V. and Wilson, C. (2002) Listening to the Secret Sounds of Earth's Atmosphere. Eos Transactions American Geophysical Union, 83, 564-565. https://doi.org/10.1029/2002eo000383

[2] Arai, N., Iwakuni, M., Watada, S., Imanishi, Y., Murayama, T. and Nogami, M. (2011) Atmospheric Boundary Waves Excited by the Tsunami Generation Related to the 2011 Great Tohoku-Oki Earthquake. Geophysical Research Letters, 38, Article ID: L00G18. https://doi.org/10.1029/2011gl049146

[3] Matoza, R.S., Hedlin, M.A.H. and Garces, M.A. (2007) An Infrasound Array Study of Mount St. Helens. Journal of Volcanology and Geothermal Research, 160, 249 262. https://doi.org/10.1016/j.jvolgeores.2006.10.006

[4] Arrowsmith, S.J., Hedlin, M.A.H., Ceranna, L. and Edwards, W. (2005) An Analysis of Infrasound Signals from the June 3rd, 2004 Fireball Over Washington State. InfraMatics, 10, 14-21.

[5] Le Pichon, A., Blanc, E. and Drob, D. (2005) Probing High-Altitude Winds Using Infrasound. Journal of Geophysical Research, 110, Article ID: D20104. https://doi.org/10.1029/2005jd006020

[6] Wilson, C.R. (1996) Auroral Infrasound Waves. Journal of Geophysical Research, 74, 1812-1836. https://doi.org/10.1029/JA074i007p01812

[7] Wilson, C.R. (2005) Infrasound from Auroral Electrojet Motions at I53US. InfraMatics, 10, 1-13.

[8] Ishihara, Y., Furumoto, M., Sakai, S. and Tsukuda, S. (2004) The 2003 Kanto Large 
Bolide's Trajectory Determined from Shockwaves Recorded by a Seismic Network and Images Taken by a Video Camera. Geophysical Research Letters, 31, Article ID: L14702. https://doi.org/10.1029/2004gl020287

[9] Yamamoto, M.-Y., Ishihara, Y., Hiramatsu, Y., Kitamura, K., Ueda, M., Shiba, Y., Furumoto, M. and Fujita, K. (2011) Detection of Acoustic/Infrasonic/Seismic Waves Generated by Hypersonic Reentry of HAYABUSA Capsule and Fragmented Parts of Spacecraft. Publications of the Astronomical Society of Japan, 63, 971-978. https://doi.org/10.1093/pasj/63.5.971

[10] Ishihara, Y., Hiramatsu, Y., Yamamoto, M.-Y., Furumoto, M. and Fujita, K. (2012) Infrasound/Seismic Observation of the Hayabusa Reentry: Observations and Preliminary Results. Earth Planets Space, 64, 655-660.

https://doi.org/10.5047/eps.2012.01.003

[11] Kanao, M., Maggi, A., Ishihara, Y., Yamamoto, M.-Y., Nawa, K., Yamada, A., Wilson, T., Himeno, T., Toyokuni, G., Tsuboi, S., Tono, Y. and Anderson, K. (2012) Seismic Wave Interactions between the Atmosphere-Ocean-Cryosphere System and the Geosphere in Polar Regions. In: Kanao, M., Takenaka, H., Murai, Y., Matsushima, J. and Toyokuni, G., Eds., Seismic Waves-Research and Analysis, InTech, Rijeka, Croatia, 1-20. https://doi.org/10.5772/23410

[12] Yamamoto, M.-Y., Ishihara, Y. and Kanao, M. (2013) Infrasonic Waves in Antarctica: A New Proxy for Monitoring Polar Environment. International Journal of Geosciences, 4, 797-802. https://doi.org/10.4236/ijg.2013.44074

[13] Ishihara, Y., Kanao, M., Yamamoto, M.-Y., Toda, S., Matsushima, T. and Murayama, T. (2015) Infrasound Observations at Syowa Station, East Antarctica: Implications for Detecting the Surface Environmental Variations in the Polar Regions. Geoscience Frontiers, 6, 285-296.

[14] Murayama, T., Kanao, M., Yamamoto, M.-Y., Ishihara, Y., Matshushima, T. and Kakinami, Y. (2015) Infrasound Array Observations in the Lützow-Holm Bay region, East Antarctica. Polar Science, 9, 35-50.

[15] Kanao, M., Maggi, A., Ishihara, Y., Stutzmann, E., Yamamoto, M.-Y. and Toyokuni, G. (2013) Characteristic Atmosphere-Ocean-Solid Earth Interactions in the Antarctic Coastal and Marine Environment Inferred from Seismic and Infrasound Recording at Syowa Station, East Antarctica. In: Hambrey, M.J., et al., Eds., Antarctic Palaeoenvironments and Earth-Surface Processes, ISAES Vol. III, Geological Society, London, Special Publications, Vol. 381, 469-480.

https://doi.org/10.1144/SP381.8

[16] Grob, M., Maggi, A. and Stutzmann, E. (2011) Observations of the Seasonality of the Antarctic Microseismic Signal, and Its Association to Sea Ice Variability. Geophysical Research Letters, 38, Article ID: L11302. https://doi.org/10.1029/2011gl047525

[17] Hedlin, M.A.H. and Alcoverro, B. (2005) The Use of Impedance Matching Capillaries for Reducing Resonance in Rosette Infrasonic Spatial Filters. The Journal of the Acoustical Society of America, 117, 1880-1888. https://doi.org/10.1121/1.1760778

[18] Hanson, J., Bras, R.L., Brumbaugh, D., Guern, J., Dysart, P. and Gault, A. (2001) Operational Processing of Hydroacoustics at the Prototype International Data Center. In: de Groot-Hedlin, C. and Orcutt, J., Eds., Monitoring the Comprehensive Nuclear-Test-Ban Treaty: Hydroacoustics, Birkhäuser, Basel, 425-456. https://doi.org/10.1007/978-3-0348-8270-5_2 
Submit or recommend next manuscript to SCIRP and we will provide best service for you:

Accepting pre-submission inquiries through Email, Facebook, LinkedIn, Twitter, etc. A wide selection of journals (inclusive of 9 subjects, more than 200 journals)

Providing 24-hour high-quality service

User-friendly online submission system

Fair and swift peer-review system

Efficient typesetting and proofreading procedure

Display of the result of downloads and visits, as well as the number of cited articles Maximum dissemination of your research work

Submit your manuscript at: http://papersubmission.scirp.org/

Or contact inframatics@scirp.org 